\title{
Muerte súbita en un varón con astrocitoma no diagnosticado
}

\section{Sudden death in a male due to undiagnosed astrocytoma}

\section{Resumen}

El diagnóstico de tumoraciones cerebrales en los servicios de patología forense es muy poco frecuente y suelen llegar a ellos ya sea como consecuencia de muertes súbitas o en el contexto de denuncias por mala praxis médica. Dentro de la escasa frecuencia, la mayoría de ellos son únicamente hallazgos incidentales de autopsia, como en el caso de muchos meningiomas, pero en otros puede ser la causa de muerte.

Presentamos el caso de un varón paquistaní de 40 años, con barrera idiomática, que consultó en un servicio de urgencias por un cuadro de cefalea, náuseas y vómitos y que falleció después del alta médica con el diagnóstico de cuadro respiratorio de vías altas. La autopsia y los estudios anatomopatológicos evidenciaron un astrocitoma grado II.

Palabras clave: Patología forense. Tumor cerebral. Astrocitoma. Muerte súbita.

\section{Abstract}

Brain tumors are seldom studied in forensic pathology services and they are seen in circumstances such as sudden unexpected death or in malpractice complaints. In most cases they are incidental findings, like meningioma, and in few cases they are the cause of death. We present the case of a 40 years old male Pakistani with linguistic barrier suffering from headache and vomiting who was diagnosed as a flue and died suddenly. Forensic autopsy and histopathologic studies showed a grade II astrocytoma.

Key words: Forensic pathology. Brain tumor. Astrocytoma. Sudden death.

\section{Introducción}

Los tumores cerebrales son una causa poco frecuente de muerte diagnosticada en los servicios de patología forense. Presentamos un caso de un varón de 40 años con barrera idiomática que consultó en urgencias por cefalea, náuseas y vómitos, siendo diagnosticado de cuadro respiratorio de vías altas y dado de alta. Falleció al día siguiente y mediante estudio histopatológico se diagnosticó un astrocitoma grado II que debutó como muerte súbita. Consideramos que éste es un caso de interés médico forense dada la escasa frecuencia de las muertes súbitas como consecuencia de un tumor cerebral no diagnosticado previamente.

\section{Presentación del caso}

Varón de 40 años, paquistaní, que acudió a un servicio de urgencias hospitalario llevado en ambulancia. Constaba en el informe médico en el apartado motivo de consulta: "cefalea, náuseas y vómitos, barrera idiomática total y sin hábitos tóxicos según el acompañante". Como antecedentes patológicos se describía en el mismo: "diabetes mellitus tipo 2 en tratamiento con antidiabéticos orales (hidrocloruro de metformina) desde hace un mes". En el apartado de enfermedad actual se hacía las siguientes menciones: "paciente que cursa con cuadro respiratorio alto, refiere persistencia de cefalea, náuseas y vómitos de contenido alimentario, dolor epigástrico
M. Subirana Domènech ${ }^{1}$

JC. Canós Villena ${ }^{2}$

G. Font Valsecchi ${ }^{1}$

I. Galtés Vicente ${ }^{1}$

J. Castellà García ${ }^{1}$
Correspondencia: Dra. Mercè Subirana. Servicio de Patología Forense. Zona Sur. Instituto de Medicina Legal de Catalunya.

Ciutat de la Justicia.

Edificio G.

Gran Vía Corts Catalanes, 111. 08014 Barcelona.

E-mail:

25402msd@comb.cat

Fecha de recepción: 1.JUL.2011

Fecha de aceptación: 2.SEP.2011 
urente, sin diarrea, sin disnea, sin diaforesis. Exploración física: tensión arterial 156/96 mmHg, frecuencia cardíaca $70 \mathrm{l} / \mathrm{m}$, temperatura axilar: $35.7^{\circ} \mathrm{C}$ y glicemia 156 mg/dL". Se describía además: "buen estado general, sobrepeso, Glasgow 15. Pupilas isocóricas, fotorreactivas, sin nistagmus patológicos ni alteraciones de la movilidad. Murmullo vesicular presente en ambos hemicampos, no crepitantes, no sibilantes. Ruidos cardíacos rítmicos de buena intensidad, sin soplos, sin chasquidos, ingurgitación yugular y reflejo hepatoyugular negativos, no signos de trombosis venosa profunda. Abdomen blando, depresible, doloroso a la palpación difusa de predominio epigástrico. McBurney y Murphy negativos, no masas ni visceromegalias". Constaba como tratamiento que se le administró en urgencias: dexketopropofeno $50 \mathrm{mg}$ y metoclorpramida $10 \mathrm{mg}$ intramusculares. Fue dado de alta a las dos horas del ingreso en el servicio de urgencias con la prescripción de: "seguir tratamiento prescrito previamente, educación en signos de alarma y control médico en dos días". Al día siguiente murió. Se practicó la autopsia judicial motivada por ser una muerte súbita sin que constara denuncia contra el servicio hospitalario que le atendió el día anterior.

\section{Hallazgos de autopsia}

Los hallazgos más destacables fueron un edema cerebral (cerebro de $1550 \mathrm{~g}$ ), desplazamiento de línea media secundario a efecto masa por lesión con componente quístico (Figuras 1 y 2). Se evidenció además un desgarro de la mucosa gastroesofágica probablemente secundaria a los vómitos. El resto de hallazgos de autopsia no mostraban otras alteraciones.

El estudio toxicológico fue negativo y el estudio histopatológico demostró la presencia de proliferación astrocitaria moderadamente diferenciada, con citoplasmas no evidentes, pleomorfismo y cambios de hipercromasia nucleares focales, ocasionales gemistocitos asociados, background propio fibrilar y ausencia de fibras de Rosenthal. No se reconocían mitosis, proliferación neovascular ni necrosis. La tinción inmunohistoquímica fue positiva para GFAP (Glial Fibrillary Acid Protein) por lo que se diagnosticó un astrocitoma grado II con edema asociado (Figuras 3 y 4 ).

\section{Discusión}

Durante el primer contacto en urgencias con el paciente inmigrante existe una barrera lingüística recíproca, la comunicación es ardua y difícil llegando a ser una odisea la obtención de datos durante la anamnesis ${ }^{1}$, incluso con un interrogatorio mediado por un acompañante del paciente. Por tanto, puede llevar a dificultades diagnósticas, como en el presente caso, en el que el diagnóstico de un tumor cerebral quedó fatalmente enmascarado hasta la práctica de la autopsia médico legal.

En la casuística médico legal los tumores cerebrales son responsables de la muerte de entre un 0,16 y $0,17 \%{ }^{2}$ y la forma de debut de muerte más frecuente es en forma de hemorragia intracerebral no traumática como primera manifestación en un $8 \%{ }^{3}$.

Los astrocitomas son los tumores primarios cerebrales más frecuentes, con una frecuencia de un $60 \% 4$. De acuerdo con la OMS se clasifican según su nivel de malignidad en cuatro grados: desde el astrocitoma pilocítico (grado I), astrocitoma difuso (grado II), astrocitoma anaplásico (grado III), hasta el glioblastoma multiforme (grado IV) ${ }^{4}$ siendo éste el tumor primario diagnosticado con mayor frecuencia ${ }^{5-7}$. Todos ellos, a pesar de compartir origen celular, son altamente variables en su aspecto macro y microscópico, localización anatómica y síntomas clínicos ${ }^{8}$. Centrándonos en el caso de estudio, en el que se diagnosticó un astrocitoma grado II, la literatura médica muestra que estas neoplasias representan el $15 \%$ de los astrocitomas y el rango de edad de presentación es entre los 20 y los 45 años $^{4}$. Se localizan con mayor frecuencia en hemisferios cerebrales: especialmente lóbulos frontales o parietales, médula espinal y con menor frecuencia en cerebelo ${ }^{8}$. Desde el punto de vista clínico se ha asociado astrocitoma con epilepsia ${ }^{9}$, pero en el caso presentado no se recogió este evento entre los antecedentes patológicos pero sí que, reevaluando el caso y tras los hallazgos de autopsia, orientamos a que cuando fue visitado en urgencias sufría síntomas de hipertensión endocraneal con cefalea y vómitos que llegaron a desgarrar la unión gastroesofágica y podemos pensar, sin poder corroborarlo, que quizás la diabetes tipo II de un mes de evolución, pudiera ser una hiperglucemia de origen central.

El aspecto macro de los astrocitomas difusos, como el presentado (grado II), es independiente del crecimiento y dependerá de si tiene degeneración quística o no. El volumen es altamente variable: desde varios centímetros a poder llegar a ocupar un lóbulo. Los de crecimiento lento tienen bordes infiltrantes, no son capsulados y forman cavidades, como el caso objeto de discusión. Puede haber microquistes, especialmente en las formas protoplasmáticas. La confluencia de quistes pueden ocasionar, como el estudio realizado, tumores quísticos relativamente grandes por degeneración quística o mucoide o en 

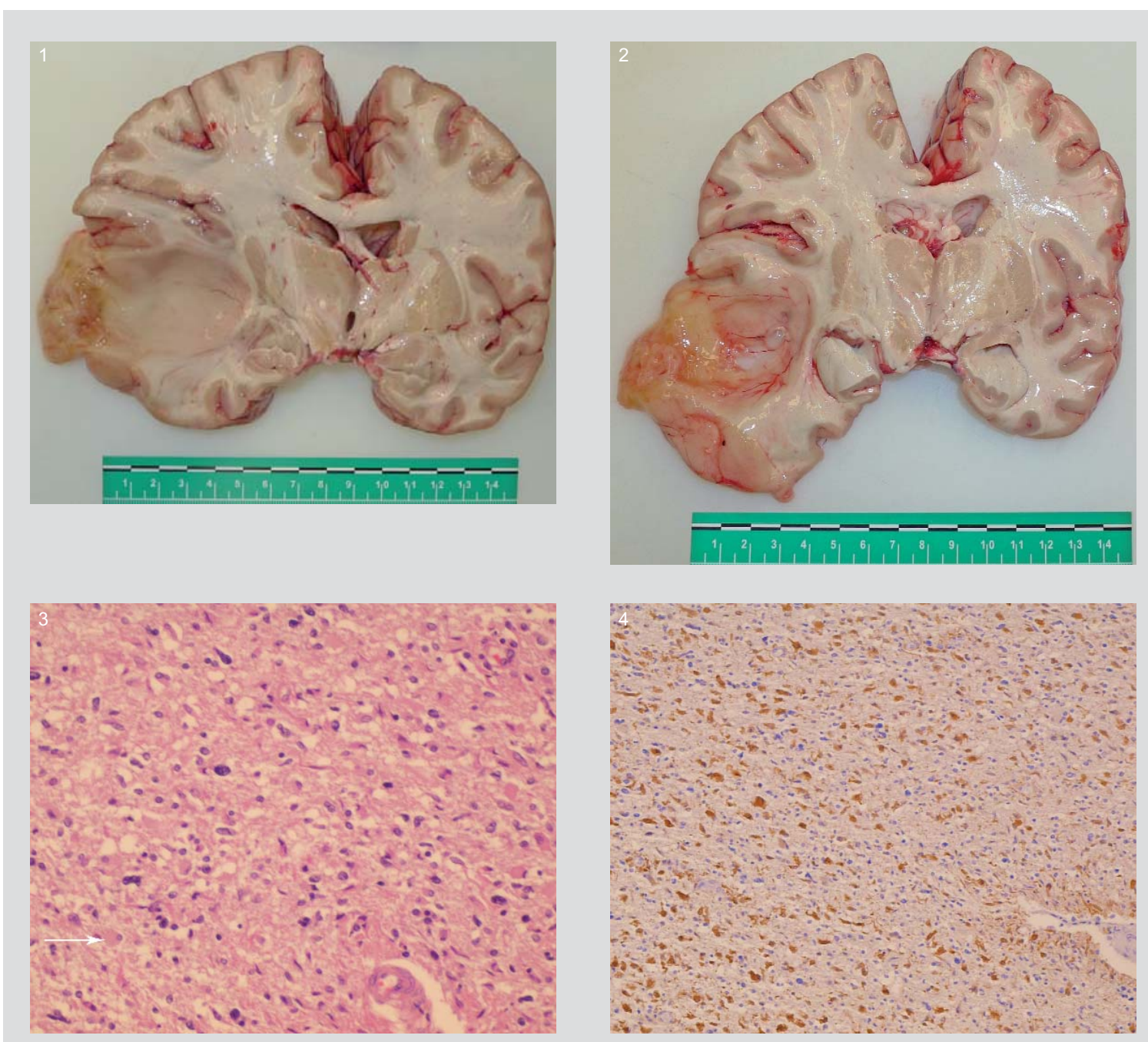

Figura 1.

Edema cerebral,

desplazamiento de línea media, masa quística en sustancia blanca en lóbulo temporal derecho, no capsulada.

Figura 2.

Visión posterior de masa sólido quística en lóbulo temporal derecho menos bien delimitada que en la visión anterior que se muestra en la Figura 1.

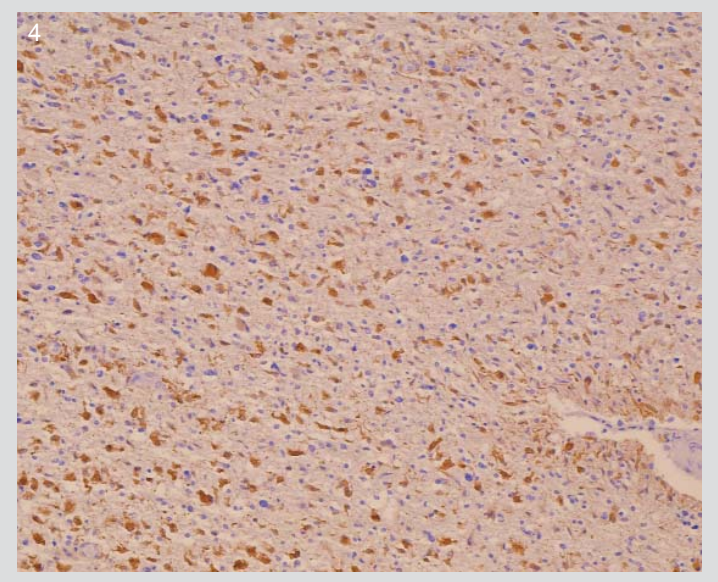

Figura 3.

Hipercromasia nuclear y ocasionales gemistocitos: uno de ellos señalado con una flecha. H-E: 400X.

\section{Figura 4.}

Inmunohistoquímica: GFAP (Glial Fibrillary Acid Protein): positividad en los astrocitos 200X. algunos casos, una pequeña porción de tumor puede incluso proyectarse dentro de una cavidad quística relativamente voluminosa. Si se limitan a la sustancia blanca pueden ser difícilmente identificables con replección y blancura ebúrnea de la zona afectada. Como el tumor suele ser más compacto que el cerebro adyacente, la palpación puede ser de gran ayuda. En los casos de crecimiento rápido se producen normalmente fenómenos de necrosis, edema intenso y la presentación de hemorragia es poco frecuente.

Microscópicamente se caracteriza por proliferación astrocitaria con patrón de crecimiento difuso con baja celularidad, escasa atipia y muy ocasionales mitosis. La citomorfología puede variar considerablemente desde fibrilar hasta tipo gemistocítico.
La utilización de marcadores de inmunohistoquímica como la GFAP (Glial Fibrillary Acid Protein), cuya positividad confirma el origen astrocitario de la neoplasia, puede ser útil para su diagnóstico como fue en el caso presentado ${ }^{8}$. En concordancia con los criterios de la OMS, el caso reportado, cumple los criterios de astrocitoma difuso grado II.

Por lo tanto, y a modo de conclusión, consideramos que la muerte en el caso objeto de presentación fue como consecuencia del edema cerebral provocado por un astrocitoma difuso grado II en un individuo en el que la sintomatología de hipertensión endocraneal acompañante no fue probablemente interpretada de forma correcta por la barrera idiomática. 


\section{Agradecimientos}

Al facultativo Agustí Mora, la Dra. Amparo Arroyo, jefa de Servicio del Laboratorio del Instituto de Medicina Legal de Catalunya (IMLC) y resto del personal de laboratorio por su colaboración en las pruebas complementarias realizadas.

A los técnicos del Servicio de Patología Forense del Instituto de Medicina Legal de Catalunya (IMLC) y

\section{Bibliografía}

1. Parrilla Ruiz FM, et al. Reflexiones de la asistencia sanitaria al inmigrante en una unidad de urgencias. Medicina de familia (And). 2003;3:195-8.

2. Di Maio V, Di Maio D. Forensic pathology. 2nd ed. Boca Raton: Editorial CRC Press, 2001

3. Black M, Graham DI. Sudden unexplained death in adults caused by intracranial pathology. J Clin Pathol. 2002;55:44-50.

4. Louis DN, et al. The 2007 WHO classification of tumours of the central nervous system. Acta Neuropathol. 2007;114 (2):97-109.

5. Shiferaw K, et al. Sudden, unexpected death due to undiagnosed frontal glioblastoma in a schizophrenic patient. Forensic Sci Int. 2006;158:200-3. personal del Instituto Nacional de Toxicología y Ciencias Forenses (INTyCF) de Barcelona por su constante dedicación y entusiasmo.

A Celia Rudilla, de la Biblioteca del Instituto de Medicina Legal de Catalunya (IMLC) por su incansable búsqueda de artículos.

A Eduard Aizpun y Miguel Galdo por su constante colaboración.
6. Matshke J, Tsokos M. Sudden unexpected death due to undiagnosed glioblastoma: report of three cases and review of the literature. Int J Legal Med. 2005; 119:280-4

7. Vougioklakis T, Mitselou A, Agnantis N. Sudden death due to primary intracranial neoplasms: a forensic autopsy study. Anticancer Res. 2006;26: 2463-6.

8. Itabashi $\mathrm{HH}$, et al. Brain Tumors. En: Forensic neuropathology: a practical review of the fundamentals. Oxford: Elsevier Academic Press, 2007. pp 359-94.

9. Prahlow JA, et al. Sudden death in epilepsy due to an isolated subependymal giant cell astrocytoma of the septum pellucidum. Am J Forensic Med Pathol. 1995; 16:30-7. 